Objectives: This abstract presents results from three clinical trials of infliximab biosimilar, BCD-055, including comparative data on pharmacokinetics (PK), efficacy and safety in a variety of patient populations.

Methods: All three studies were conducted as international multicenter randomized double-blind studies in direct comparison with innovator IFX. ASART-1 study (Phase 1, PK study) and ASART-2 study (Phase 3, efficacy and safety study) were conducted in patients with AS. After the screening patients were stratified by CRP and BASDAl score, randomized (1:1 ratio in ASART-1; 2:1 ratio in ASART-2) into 2 arms and received BCD-055 or innovator IFX at a dose $5 \mathrm{mg} / \mathrm{kg} \mathrm{IV} \mathrm{on} \mathrm{day}$ 1 wk $0,2,6$ and then every 8 wks (up to wk 54). LIRA study (Phase 3 study) was conducted in patients with active RA who were stratified by age and DAS28 score, randomized (2:1) into 2 arms and received BCD-055 or innovator IFX at a dose $3 \mathrm{mg} / \mathrm{kg}$ IV on day $1 \mathrm{wk} 0,2,6$ and then every 8 wks (up to wk 54).

Results: A total of 91 patients were enrolled in ASART-1 study, 198 patients - in ASART-2 study and 195 patients - in LIRA study in Russia and Belarus.

PK characteristics were equivalent for BCD-055 and innovator IFX. After the single administration $90 \% \mathrm{Cl}$ for the ratio of geometric means for $\mathrm{AUC}_{0-336}$ was $86.40 \%$ - $110.09 \%$, for $\mathrm{C}_{\max }-82.70 \%-109.83 \%$. After multiple-dose administration $90 \% \mathrm{Cl}$ for the ratio of geometric means for $\mathrm{AUC}_{0 \text {-tau }}$ was $81.35 \%-121.13 \%$, for $\mathrm{C}_{\max , \mathrm{ss}}-90.16 \%-117.32 \%$.

Efficacy: BCD-055 is non-inferior to innovator IFX both in RA and AS patients: ACR20 at wk 14 was reached by $75.83 \%$ of patients in BCD-055 group and $74.19 \%$ in innovator IFX group $(\mathrm{p}=0.951,95 \% \mathrm{Cl}$ for difference in proportion [-12.90\%; $16.18 \%]$, margin $-20 \%)$, ASAS20 at wk 30 - by $81.30 \%$ and $67.74 \%$ respectively $(\mathrm{p}=0.061,95 \% \mathrm{Cl}$ for difference in proportion $[-1.18 \% ; 28.28 \%]$, margin $-17.5 \%$ ).

Safety: BCD-055 and innovator IFX showed highly similar safety profiles in all three studies without cases of unexpected toxicity. The rates of AEs were equivalent for both drugs and varied from $47 \%$ in patients with AS to $53 \%$ in patients with RA. Immunogenicity assessment didn't find any significant difference between BCD-055 and innovator IFX, anti-drug antibodies occurred at the same rate irrespectively to the group.

Conclusions: BCD-055 is highly similar to innovator IFX in patients with active RA and in patients with AS in terms of efficacy, safety and PK.

References:

[1] EMA/CHMP/BMWP/403543/2010.

Disclosure of Interest: L. Denisov: None declared, I. Gordeev: None declared, V. Mazurov: None declared, A. Lila: None declared, E. Zonova: None declared, O. Nesmeyanova: None declared, E. llivanova: None declared, T. Plaksina: None declared, A. Eremeeva Employee of: JCS BIOCAD, A. Artemeva Employee of: JCS BIOCAD, E. Chernyaeva Employee of: JCS BIOCAD, R. Ivanov Employee of: JCS BIOCAD, S. Pimanov: None declared, E. Kunder: None declared, N. Soroka: None declared

DOI: 10.1136/annrheumdis-2017-eular.4723

\section{FRI0209 REAL-LIFE SAFETY PROFILE OF BIOSIMILAR ADALIMUMAB IN PATIENTS WITH INFLAMMATORY ARTHRITIC CONDITIONS}

\section{Kaushik, S. Apparao. Arthritis \& Rheumatism Centre, Chennai, Chennai, India}

Background: Biologic therapies have dawned a new era in the management of patients with chronic inflammatory arthritis by nudging the goal post from control to induction of remission. Adalimumab, a TNF- $\alpha$ inhibitor, has proven to be safe and effective in improving the disease activity and quality of life in patients with conditions like rheumatoid arthritis (RA) and ankylosing spondylitis (AS). ${ }^{1,2}$ A biosimilar adalimumab (developed by Cadila Healthcare Ltd., India) has been approved for clinical use in 2014 in India. While the initial biosimilarity has been established for physicochemical, functional as well as clinical efficacy and safety aspects:3,4 ongoing evaluation of safety in real-life patients is crucial for such biosimilar therapies.

Objectives: We share our experience on the real-life safety profile of biosimilar adalimumab following its clinical use in patients with RA and AS.

Methods: Patients with RA or AS treated with biosimilar adalimumab in our outpatient clinic at Arthritis and Rheumatism Centre during the period of 17 Dec 2014 to 30 Mar 2016 were considered for this analysis. The patients were prescribed biosimilar adalimumab $40 \mathrm{mg}$ subcutaneously every fortnight for a minimum of 6 months. The patients were followed up till the end of the treatment, and any safety signals or adverse events reported were collected and analysed. Results: A total of 200 patients - 119 patients with AS and 81 patients with RA - who received biosimilar adalimumab therapy for a period of 6 months were included. The median age for the group was 36 (17-68 years); and 138 patients were males. The mean BMI was 25.74 \pm 3.83 ; and the median duration of disease for the entire group was $4.54(0.5-13.5)$ years - $4.54(0.5-9.58)$ years for the patients with AS, and $4.58(2.5-13.5)$ years for the patients with RA. About $90 \%$ (181 out of 200 patients) received concomitant therapy with methotrexate. Biosimilar adalimumab therapy was well tolerated by all patients, with no serious adverse events. Adverse events were noted in only 2 patients - one patient had developed pulmonary tuberculosis in the 4th month of treatment, biosimilar adalimumab was discontinued and AKT treatment was started; while another patient experienced rise in transaminases for which, the dose of methotrexate was reduced. Overall assessment of tolerability as "Excellent" was $65.5 \%$ by the treating physician and $82 \%$ by patients.

Conclusions: To the best of our knowledge, this is the first report on "real-life" use of biosimilar adalimumab in such a large number of patients. The analysis reveals a safety and tolerability profile of biosimilar adalimumab comparable to that of the innovator product.

\section{References:}

[1] Voulgari PV, Drosos AA. Expert Opin Biol Ther. 2006; 6(12):1349-1360.

[2] Papagoras C, Voulgari PV, Drosos AA. Open Access Rheumatol. 2009 May 18:1:51-68.

[3] Bandopadhyay S, et al. Biosimilars. 2015;5:1-18.

[4] Jani RH, et al. Int J Rheum Dis. 2015 Jul 14.

Disclosure of Interest: None declared

DOI: 10.1136/annrheumdis-2017-eular.2357

\section{FRI0210 REAL-WORLD HAWK STUDY: LONG-TERM SAFETY AND EFFECTIVENESS OF ADALIMUMAB WITH HIGHER-DOSE METHOTREXATE IN JAPANESE PATIENTS WITH EARLY RHEUMATOID ARTHRITIS}

Y. Tanaka ${ }^{1}$, T. Mimori ${ }^{2}$, H. Yamanaka ${ }^{3}$, R. Nakajima ${ }^{4}$, K. Morita ${ }^{4}$, J. Kimura ${ }^{4}$, T. Takeuchi ${ }^{5}$. ${ }^{1}$ The First Department of Internal Medicine, School of Medicine, University of Occupational and Environmental Health, Kitakyushu; ${ }^{2}$ Department of Rheumatology and Clinical Immunology, Graduate School of Medicine, Kyoto University, Kyoto; ${ }^{3}$ Institute of Rheumatology, Tokyo Women's Medical University; ${ }^{4}$ AbbVie GK; ${ }^{5}$ Division of Rheumatology, Department of Internal Medicine, School of Medicine, Keio University, Tokyo, Japan

Background: TNF inhibitors are first-line biologic therapy used in combination with MTX for treatment of RA. However, in Japan, limited real-world data exist on this combination with relatively higher doses of MTX ( $>8$ to $\leq 16 \mathrm{mg} / \mathrm{week}$ ).

Objectives: The HAWK study was designed to assess real-world, long-term safety and effectiveness of the TNF inhibitor ADA with MTX ( $\geq 12 \mathrm{mg} / \mathrm{week}$ ) in Japan. Week 52 results are presented.

Methods: This multicenter, prospective, observational study, enrolled biologicnaïve, early ( $\leq 2$ years) RA patients with DAS28-CRP $>3.2$ despite MTX therapy for $\geq 3$ months. Eligible patients received ADA + MTX $(\geq 12 \mathrm{mg} /$ week at beginning of ADA) for 104 weeks. Primary endpoint was DAS28-CRP $<2.6$ at week 52. Secondary endpoints included CDAI, SDAI, HAQ-DI and inhibition of structural joint damage using the mTSS. ADRs and dosage of ADA and MTX were recorded. Results: As of April 15, 2016, 346 patients were enrolled (safety set 301; effectiveness set 293). Effectiveness set comprised $73 \%$ women; mean ( \pm SD) age, 54.3 (13.9) years; duration of RA, 12.1 (6.2) months; MTX dosage, 13.4 (1.8) mg/week; DAS28-CRP, 4.5 (0.9); and mTSS, $7.7(10.0)$ at baseline. At week 52, DAS28-CRP $<2.6$ and low disease activity $(<3.2)$ were achieved in $77 \%$ and $92 \%$ patients, respectively. Remission rates in CDAI $(\leq 2.8), \operatorname{SDAI}(\leq 3.3)$, and HAQ-DI $(\leq 0.5)$ were $49 \%, 51 \%$, and $82 \%$, respectively. Although average MTX dosage was decreased ( $\leq 2 \mathrm{mg} / \mathrm{week}$ ), unchanged, and increased ( $\geq 2 \mathrm{mg} / \mathrm{week}$ ) from baseline in $19.6 \%, 78.9 \%$, and $1.4 \%$ patients over 52 weeks, respectively, there was no significant difference in disease activity improvement across these MTX dosage groups at week $52(p=0.350)$. Structural remission rate at week 52 was $86 \%(\Delta \mathrm{mTSS} \leq 0.5)$ (Figure). A total $110 \mathrm{ADRs}$ occurred in $80(26.6 \%)$ patients, 23 were serious in $21(7.0 \%)$ patients (Table).

\begin{tabular}{lcccc}
\hline & All (N=301) & \multicolumn{2}{c}{ Serious (N=301) } \\
\hline ADR & & & & \\
$\quad$ Total & 80 & $26.6 \%$ & 21 & $7.0 \%$ \\
ADRs by SOC & & & & \\
$\quad$ Infections and infestations & 29 & $9.6 \%$ & 9 & $3.0 \%$ \\
$\quad$ Investigations & 16 & $5.3 \%$ & 1 & $0.3 \%$ \\
$\quad$ Respiratory, thoracic and mediastinal disorders & 13 & $4.3 \%$ & 3 & $1.0 \%$ \\
$\quad$ Hepatobiliary disorders & 9 & $3.0 \%$ & 0 & \\
ADRs of particular interest & & & & \\
$\quad$ Tuberculosis & 0 & & 0 & \\
$\quad$ Pneumocystis jirovecii pneumonia & 4 & $1.3 \%$ & 4 & $1.3 \%$ \\
$\quad$ Pneumonia bacterial* & 6 & $2.0 \%$ & 4 & $1.3 \%$ \\
$\quad$ Herpes zoster & 4 & $1.3 \%$ & 0 & \\
$\quad$ Malignancy (1) & 4 & $1.3 \%$ & 4 & $1.3 \%$ \\
$\quad$ Interstitial lung disease & 2 & $0.7 \%$ & 2 & $0.7 \%$ \\
$\quad$ Sepsis & 0 & & 0 & \\
$\quad$ Pancytopenia & 0 & & 0 & \\
$\quad$ Reactivation of hepatitis B & 0 & & 0 & \\
\hline
\end{tabular}

*Pneumonia, Pneumonia bacterial, Pneumonia pneumococcal, Pneumonia legionella, Pneumonia streptococcal. (1) Colon cancer, diffuse large B-cell lymphoma, ovarian cancer metastatic, lung neoplasm malignant.

Conclusions: Results show that ADA with MTX ( $\geq 12 \mathrm{mg} /$ week at the beginning) displayed a consistent safety profile and was effective with a DAS28-CRP remission rate of $77 \%$ in routine clinical practice. The ADR rate of $26 \%$ was similar to a previous, short-term (28 weeks) postmarketing surveillance report (1). References:

[1] Koike et al. Mod Rheumatol 2014; 24:390-8.

Acknowledgements: This study (NCT01736189) was funded by AbbVie GK and Eisai Co., Ltd. AbbVie participated in the collection, analysis, and interpretation of the data, and in the drafting, review, and approval of the abstract.

AbbVie GK and Eisai Co., Ltd. provided funding to EPS Corporation for data analysis and to Cactus Communications for editorial assistance.

Disclosure of Interest: Y. Tanaka Grant/research support from: Mitsubishi- 